The International Journal of Indian Psychology: Volume: 01 | Issue: 04 | ISSN 2348-5396

\title{
Emotional intelligence and self esteem of alcohol and cannabis dependents
}

\author{
Dr. Thiyam Kiran Singh*, Shivi Saxena**
}

\begin{abstract}
A total of 120 were collected out of which 60 were alcohol dependents and 60 were cannabis dependents that were diagnosed based on ICD-10 were selected from SMS Psychiatric Centre, Jaipur and other Psychiatric Centre of Jaipur. The purpose of this study is to find out emotional intelligence and self esteem of Alcohol Dependents and Cannabis Dependents. Assessment was done using Severity of Alcohol Dependents Questionnaire of Edwards (1978), Cannabis Use Disorder Identification Test (Adamson \& Sellman, 2003), Raqon Emotional Intelligence Test (Roqan, 1971) and Rosenberg Self Esteem Scale (Rosenberg, 1965). To find out severity of alcohol dependence, cannabis dependence, emotional intelligence and self esteem of alcohol dependents \& cannabis dependents. The result find alcohol dependents are poor in emotional intelligence and self esteem in comparing with cannabis dependents. The severity of alcohol dependence is negatively correlated with emotional intelligence and self esteem which tells us that with the increase in severity of dependence the emotional intelligence and self esteem of Alcohol Dependents were reduced. Similarly the severity of cannabis dependence is negatively correlated with emotional intelligence which signifies with the increase in severity of dependence the emotional intelligence of cannabis dependents were reduced but positively correlated with self esteem which acknowledge us that with the increase in severity of dependence the self esteem of cannabis dependents were increased.
\end{abstract}

Keywords: Alcohol Dependents, Cannabis Dependents, Emotional Intelligence, Self Esteem.

\section{INTRODUCTION:}

Alcohol is the most commonly used recreational drug globally and its consumption, often in large volume in India. Many families in India become ruined because of drinking habit in one or other family members. Many family members do not know how to deal with such kind of dependents members. They think it is a very huge burden on them, many times they feel as if their life becomes heal or curse because of dependents members. Many spouses refuse to settle-

*Assistant Professor and Clinical Psychologist, Dept. of Psychology, AIBAS, Amity University Rajasthan, Jaipur.

**M.Phil Clinical Psychology trainee, Dept. of Psychology, AIBAS, Amity University Rajasthan, Jaipur. 


\section{The International Journal of Indian Psychology: Volume: 01 | Issue: 04 | ISSN 2348-5396}

with Alcohol Dependents for longer span of life because of unbearable stresses of life being integrated with them so in return they separated or divorce them from their life and start living a new life. Singh and Raju (2012) found out that the overall the quality of life of Alcohol Dependents were poor. They have poor Physical, Psychological, Independence, Social, Environment and Spiritual domains. They also found out that most of the spouses of Alcohol dependents were not satisfied in their marital life towards husband. Most Alcohol Dependents were having severe depression because of unable to control over their drinking, life become unmanageable, lost prestige and social status not only that many of them also have severe level of organic brain dysfunction (Singh \& Shukla, 2012). In some low income groups spouses become sexual worker in order to earn some income and feed their children in the family. Alcohol dependents have lots of Psycho-social problems. Psychological problems like drinking in order to reduce stress, tension, anxiety, escaping from problem, blaming others, showing more aggression, preoccupation of thoughts etc. and social problems like lost of Job, breakdown of relationships, financial burden, divorce etc.. Likewise, Cannabis is also the most commonly used illicit drug in India and a significant proportion of users have symptoms of dependence. In addition, there are a number of adverse consequences of use, including an association with psychotic disorders. The present study has attempted to find out emotional intelligence and self esteem of Alcohol dependents and Cannabis dependents and also to compare Emotional Intelligence and self esteem of Alcohol dependents and Cannabis dependents so as to gain knowledge about emotional intelligence and self esteem of Alcohol dependents and Cannabis dependents and could implement in helping them in treatment once we get idea about the difference about emotional intelligence and self esteem of Alcohol dependents and Cannabis dependents as Meddock and Babbs (2006) stated there is a need for effective treatment of cannabis misuse and Alcohol Dependents.

\section{METHODOLOGY:}

\section{Objectives of the study:}

1. To find out emotional intelligence and self esteem of Alcohol dependents and Cannabis dependents.

2. To compare Emotional Intelligence and self esteem of Alcohol dependents and Cannabis dependents.

\section{Hypotheses of the study:}

1. There will be significant difference in emotional intelligence in comparison between alcohol dependents and cannabis dependents.

2. There will be significant difference in self esteem in comparison between alcohol dependents and cannabis dependents. 
The International Journal of Indian Psychology: Volume: 01 | Issue: 04 | ISSN 2348-5396

\section{Sample Size:}

The sample size consists of 120 samples out of which 60 are alcohol dependents and 60 are cannabis dependents.

\section{Alcohol Dependents:}

Inclusion Criteria:

1. Those who fulfill the criteria of Alcohol Dependents according to ICD 10.

2. Male Alcohol Dependents between the age range of 30 to 40 years.

3. Those who do not have co-morbid (Axis -IV, DSM) psychiatric Diagnosis.

4. Those who can give consent for study

Exclusion Criteria:

1. Those who do not fulfill the criteria of Alcohol Dependents According to ICD 10.

2. Female Alcohol Dependents

3. Social or Occasional drinkers

4. Those who cannot give consent for study

\section{Cannabis Dependents:}

Inclusion Criteria:

1. Those who fulfill the criteria of Cannabis Dependents according to ICD 10.

2. Male Cannabis Dependents from the age of 30 to 40 years.

3. Those who do not co-morbid (Axis -IV, DSM) psychiatric Diagnosis.

4. Those who can give consent for study.

Exclusion Criteria:

1. Those who do not fulfill the criteria of Cannabis Dependents According to ICD 10.

2. Female Cannabis Dependents.

3. Social or Occasional user.

4. Those who cannot give consent for study. 


\section{The International Journal of Indian Psychology: Volume: 01 | Issue: 04 | ISSN 2348-5396}

\section{Tools Used:}

\section{Severity of Alcohol Dependent Questionnaire (SADQ)}

The SADQ is a short, easy-to-complete, self-administered, 20-item questionnaire designed to measure severity of dependence on alcohol as formulated by Edwards \& Gross (1976) and Edwards (1978). There are five subscales with four items in each: Physical Withdrawal, Affective Withdrawal, Withdrawal Relief Drinking, Alcohol Consumption, and Rapidity of Reinstatement. Each item is scored on a 4-point scale, ranging from "Almost Never" to "Nearly Always," resulting in a corresponding score of 0 to 3 . Thus the total maximum score possible is 60 and the minimum is 0. The original SADQ as first described in 1979 and further refined in 1983 is designed purely for use with populations of problem drinkers attending treatment facilities of various kinds. The SADQ has been widely used with such groups, and norms exist for inpatient treatment units, outpatient clinics,community-based services, and controlled drinking program attenders, to name but a few. Test rest reliability of SADQ is 0.85 .

\section{Cannabis Use Disorder Identification Test (CUDIT)}

The Cannabis Use Disorders Identification Test (Adamson \& Sellman, 2003) was used to assess cannabis use behavior. The CUDIT is a ten item questionnaire designed to screen for evidence of hazardous or harmful cannabis use and covers the domains of cannabis consumption, cannabis smoking behavior and cannabis related problems. Participants are required to read a statement and circle the answer which corresponds to their pattern of use 0.78. The CUDIT has a possible range of zero and forty. Each question is scored from 0 to 4 , with an example item being " How often were you stoned for six or more hours. The CUDIT demonstrates adequate reliability (Adamson \& Sellman, 2003).

\section{Roqan Emotional Intelligence Test (REIT)}

This test was developed by Roqan (1971). This test has 30 items, self administered test and cultural free. The reliability and validity of the test is 0.7 and 0.83 indicating highly reliable and valid. This test is used for adolescents.

\section{Rosenberg Self Esteem scale (RSES)}

This scale has 10-item designed by Rosenberg (1965) assesses an individual's feelings of selfworth when the individual compares himself or herself to other people. The scale is an attempt to achieve a one- dimensional measure of global self esteem. It was designed to represent a continuum of self worth, with statements that are endorsed by individuals with low self-esteem to statements that are endorsed only by persons with high self-esteem. Criterion Validity: .55, Construct Validity: Correlated -.64 with anxiety, -.54 with depression, and -.43 with anomie.

\section{PROCEDURE:}

A total sample of 120 i.e. 60 Alcohol Dependents and 60 Cannabis Dependents that fulfilled ICD -10 criteria were collected from SMS Psychiatric Centre, Jaipur and other Psychiatric Centre in Jaipur. Consents were taken from both alcohol dependents and cannabis dependents about 


\section{The International Journal of Indian Psychology: Volume: 01 | Issue: 04 | ISSN 2348-5396}

research. Information was gathered about alcohol dependents and cannabis dependents using Severity of Alcohol Dependents Questionnaire (SADQ), Cannabis Use Disorder Identification Test (CUDIT). Both alcohol dependents and cannabis dependents were administered Roqan Emotional Intelligence Test (REIT) and Rosenberg Self Esteem Scale (RSES) to find out level of emotional intelligence and self esteem.

\section{STATISTICAL ANALYSIS:}

The statistical methods of: t- test, Pearson's product movement's coefficient of correlation and chi square were used with the help of statistical software namely statistical package of social sciences (SPSS 17.0).

\section{RESULTS:}

Table 1 shows comparison of Alcohol Dependents and Cannabis Dependents on Raqon Emotional Intelligence Test (REIT) and the result found significant difference in comparison of Alcohol dependents and Cannabis Dependents in Raqon Emotional Intelligence Test $\left(X^{2}=22.63\right.$, $\mathrm{P}<0.01)$ which indicates Alcohol Dependents are lower emotional intelligence compare to Cannabis Dependents. Table 2 shows comparison of Alcohol Dependents and Cannabis Dependents on Rosenberg Self Esteem Scale (RSES) and the result found significant difference in comparison of Alcohol dependents and Cannabis Dependents in Rosenberg Self Esteem Scale. $\left(\mathrm{X}^{2}=7.658, \mathrm{P}<0.01\right)$ indicating Alcohol Dependents are poor in self esteem than Cannabis Dependents. Table 3 shows correlation of Severity Alcohol Dependents Questionnaire (SADQ) and Raqon emotional intelligence (REIT) of Alcohol Dependents and the result found negative correlation (-.056) which tells us that with the increase in severity of dependence the emotional intelligence of Alcohol Dependents were reduced. Table 4 shows correlation of Severity Alcohol Dependents Questionnaire (SADQ) and Rosenberg Self Esteem Scale (RSES) of Alcohol Dependents and the result proclaim negative correlation (-.093) which tells us that with the increase in severity of dependents the self esteem of Alcohol Dependents were reduced. Table 5 shows correlation of Cannabis Use Dependents Identification Test (CUDIT) and Roqan Emotional Intelligence Test (REIT) of Cannabis Dependents and the rest found negative correlation (-0.083) which signifies with the increase in severity of dependence the emotional intelligence of cannabis dependents were reduced. Table 6 shows correlation of Cannabis Use Dependents Identification Test (CUDIT) and Rosenberg Self Esteem Scale (RSES) of Cannabis Dependents and the result enlightened positive correlation (.099) which acknowledges us that with the increase in severity of dependence the self esteem of cannabis dependents were increased.

\section{Discussion:}

The study found significant difference in comparison of Alcohol dependents and Cannabis Dependents in Roqan Emotional Intelligence Test and as well as Rosenberg Self Esteem Scale which indicates Alcohol Dependents have lower emotional intelligence and self esteem compare to Cannabis Dependents. The reason may be because alcohol dependents due to 


\section{The International Journal of Indian Psychology: Volume: 01 | Issue: 04 | ISSN 2348-5396}

their prolong habit of drinking they lost confidence, self esteem and feel worthless of life. Supportively, DeHart et al (2009) examined the relations among implicit self-esteem, interpersonal interactions and alcohol consumption in college students. Multilevel analyses revealed that students with low implicit self-esteem drank more on days when they experienced more negative interpersonal interactions. These findings suggest that people with low implicit self-esteem may unintentionally drink as a way to regulate unfulfilled needs for acceptance. Reay (2006) found in his study that drug user scored lower on the questionnaire which had been employed for the assessment of Emotional Intelligence. Likewise, Walant (1995) posits that persons vulnerable to alcohol and drug abuse have suffered self esteem neglect of their attachment needs and compensate by artificially inducing merger states through their use of drugs and alcohol.

This study found, with the increase in severity of dependence the emotional intelligence and self esteem of Alcohol Dependents were reduced. Similarly, even for Cannabis Dependents with the increase in severity of dependence the emotional intelligence of cannabis dependents were reduced. This may be because they lost self confidence, increase cognitive dysfunctions and also poor in judgment. Supportively, Goleman (1995) ascertain that low Emotional Intelligence (EI) was a major factor in drug and alcohol addiction. This study found that EI scores were significantly related to addiction levels but this was fully mediated by the psychological distress variable. Zukauskas, et al. (2001) found alcohol and cannabis abuses leads to stress which plays an important role in human life. Under normal condition it has a favourable influence. However constant pathological stress can be harmful. It also leads to loss of self confidence and poor judgment.

Whereas the in the case of cannabis dependents study found, with the increase in severity of dependence the self esteem of cannabis dependents were increased. This may be because they have poor judgment, attention, decision making and their cognitive thinking capacity. Supportively, West and Sweeting (1997) found that 15 year olds with higher selfesteem were more likely to take drugs like cannabis and have had sexual experiences. Medina et al. (2009) found that increase volume in the prefrontal cortex was associated with poorer executive functioning among cannabis users. Batalla et al. (2013) found cannabis use has been associated with a range of acute and chronic mental health problems such as neuro-cognitive alterations, anxiety, depression as well as increase risk of psychotic symptoms and disorders, the severity of these effects being dependent on frequency of use, age of onset and genetic vulnerability. Continuous use of cannabis leads to brain lesion at prefrontal cortex, cingulated cortex, basal ganglia, medial temporal areas etc. which leads to poor judgment, decision making, attention, psychomotor speed and memory. 


\section{The International Journal of Indian Psychology: Volume: 01 | Issue: 04 | ISSN 2348-5396}

\section{CONCLUSION:}

From this study it can be concluded that alcohol dependents are poor in emotional intelligence and self esteem in comparing with cannabis dependents. The severity of alcohol dependence is negatively correlated with emotional intelligence and self esteem which tells us that with the increase in severity of dependence the emotional intelligence and self esteem of Alcohol Dependents were reduced. Similarly, the severity of cannabis dependence is negatively correlated with emotional intelligence which signifies with the increase in severity of dependence the emotional intelligence of cannabis dependents were reduced but positively correlated with self esteem which acknowledge us that with the increase in severity of dependence the self esteem of cannabis dependents were increased.

\section{REFERENCES:}

1. Adamson, S. J., \& Sellman, D. J. (2003). A prototype screening instrument for Cannabis use disorder: The cannabis use disorders identification test (CUDIT) in an alcohol dependence clinical sample. Drug and Alcohol Review, 22(1), 309-315.

2. Batalla, A., Bhattacharyya, S., Yücel, M., Poli, P., \& Crippa, J.A. (2013). Structural and Functional Imaging Studies in Chronic Cannabis Users: A systematic Review of Adolescent and Adult Findings. Retrieved from: http://www.plosone.org/article/info\%3Adoi\%2F10.1371\%2Fjournal.pone.0055821 on 28/4/2014.

3. DeHart,T., Tennen, H., Armeli, S., Todd, M., \& Mohr, C. (2009). A Diary Study of Implicit Self-esteem, Interpersonal Interactions and Alcohol Consumption in College Students. Journal of Experimental Soc Psychol. 45(4), 720-730. Retrieved from:

http://www.ncbi.nlm.nih.gov/pmc/articles/PMC2717559/ on 26/4/2014.

4. Edwards, G. \& Gross, M. M. (1976) Alcohol dependence: provisional description of a clinical syndrome, British Medical Journal, 1, 1058-1061.

5. Edwards, G. (1978). The alcohol dependence syndrome: A concept as stimulus to enquiry. British Journal of Addiction, 81, 171-184.

6. Goleman, D. (1995). Emotional intelligence. New York: Bantam.

7. Meddock, C., \& Babbs, M. (2006). Interventions for cannabis misuse. Advances in Psychiatric treatment. Retrieved from: http://apt.rcpsych.org/content/12/6/432.full on 22/4/2014. 
The International Journal of Indian Psychology: Volume: 01 | Issue: 04 | ISSN 2348-5396

8. Medina, K.L., \& Schweinsburg, A.D. (2009). Effects of alcohol and combined marijuana and alcohol use during adolescence on hippocampal volume and asymmetry. Neurotoxical Teratol, $29(1), 141-152$.

9. Reay (2006). In Singh, M. (2012). A Comparative study of Emotional Intelligence \& Personality of Alcolics \& Drug addicts and Non Alcoholics \& Nno Drug Addicts. Retrieved From: http://shodh.inflibnet.ac.in/bitstream/123456789/88/2/02_chapters.pdf on 26/4/2014.

10. Rosenberg, M. (1965). Society and the adolescent self-image. Princeton, NJ: Princeton University Press.

11. Singh, T.K., \& Raju, M.V.R. (2012). Alcohol Dependents: Quality of life and marital satisfaction with their spouses. Indian Journal of Health and Wellbeing, 3 (1), 75-79.

12. Singh, T.K., \& Shukla, P.N. (2012). Alcohol Dependents: Their associated depression and pattern on Nehor Benson Test, Indian Journal of Health and Wellbeing, 3 (1), 137-140.

13. Walant, K.B. (1995). Creating the capacity for attachment: Treating addiction and the alienated self. Northvali, NJ: Jason Aronson.

14. West, P. \& Sweeting, H. (1997). Lost souls and rebels: a challenge to the assumption that low self-esteem and unhealthy lifestyles are related. Health Education, 97, 161-167.

15. Zukauskas, G., Dapsys, K., Jasmontaite, E., \& Susinskas, J. (2001). Some psychosocial problems of Police officers in Lithuania. An International Journal of Police Strategies \& Management, 24 (3), 301-309.

\section{Tables:}

Table 1: Comparison of Alcohol Dependents and Cannabis Dependents on Raqon Emotional Intelligence Test (REIT)

\begin{tabular}{|l|l|l|l|l|l|l|}
\hline Variable & Group & \multicolumn{2}{|l|}{$\begin{array}{l}\text { Alcohol } \\
\text { Dependents }\end{array}$} & \multicolumn{2}{l|}{$\begin{array}{l}\text { Cannabis } \\
\text { Dependents }\end{array}$} & $\mathrm{X}^{2}$ \\
\hline \multirow{3}{*}{ REIT } & & $\mathrm{N}$ & $\%$ & $\mathrm{~N}$ & $\%$ & \multirow{3}{*}{$22.63^{* *}$} \\
\cline { 2 - 7 } & Low & 41 & 68.3 & 15 & 25.0 & \\
\cline { 2 - 7 } & Normal & 19 & 31.7 & 45 & 75.0 & \\
\hline \multicolumn{2}{|l|}{ Total } & 60 & 100 & 60 & 100 & \\
\hline
\end{tabular}

\footnotetext{
** Significant at 0.01 level

*Significant at 0.05 level
} 
The International Journal of Indian Psychology: Volume: 01 | Issue: 04 | ISSN 2348-5396

Table 2: Comparison of Alcohol Dependents and Cannabis Dependents on Rosenberg Self Esteem Scale (RSES)

\begin{tabular}{|l|l|l|l|l|l|l|}
\hline Variable & Group & \multicolumn{2}{|l|}{$\begin{array}{l}\text { Alcohol } \\
\text { Dependents }\end{array}$} & \multicolumn{2}{l|}{$\begin{array}{l}\text { Cannabis } \\
\text { Dependents }\end{array}$} & \multirow{2}{*}{$\mathrm{X}^{2}$} \\
\hline \multirow{3}{*}{ RES } & & $\mathrm{N}$ & $\%$ & $\mathrm{~N}$ & $\%$ & \multirow{3}{*}{$7.685^{* *}$} \\
\cline { 2 - 7 } & Low & 21 & 35.0 & 8 & 13.3 & \\
\cline { 2 - 7 } & Normal & 39 & 65.0 & 52 & 86.7 & \\
\cline { 1 - 6 } Total & 60 & 100 & 60 & 100 & \\
\hline
\end{tabular}

** Significant at 0.01 level

*Significant at 0.05 level

Table 3: Correlation of Severity Alcohol Dependents Questionnaire (SADQ) and Raqon emotional intelligence (REIT) of Alcohol Dependents

\begin{tabular}{|c|c|c|c|c|c|}
\hline Group & \multicolumn{4}{|c|}{ SADQ } & \multirow[t]{2}{*}{$\mathrm{R}$} \\
\hline \multirow{5}{*}{ REIT } & Variable & Mild & Moderate & Severe & \\
\hline & \multirow[t]{2}{*}{ Low } & 4 & 2 & 35 & \multirow[t]{4}{*}{-0.056} \\
\hline & & $6.7 \%$ & $3.3 \%$ & $71.4 \%$ & \\
\hline & \multirow[t]{2}{*}{ Normal } & $1 \cap \mathrm{C}$ & 4 4elne & 1401 & \\
\hline & & $1.7 \%$ & $6.7 \%$ & $23.3 \%$ & \\
\hline \multirow[t]{2}{*}{ Total } & & 5 & 6 & 49 & 60 \\
\hline & & $8.3 \%$ & $10.0 \%$ & $81.7 \%$ & $100 \%$ \\
\hline
\end{tabular}

\section{** Significant at 0.01 level}

*Significant at 0.05 level

Table 4: Correlation of Severity Alcohol Dependents Questionnaire (SADQ) and Rosenberg Self Esteem Scale (RSES) of Alcohol Dependents

\begin{tabular}{|c|c|c|c|c|c|}
\hline Group & \multicolumn{4}{|c|}{ SADQ } & \multirow[t]{2}{*}{$\mathrm{R}$} \\
\hline \multirow{5}{*}{ RES } & Variable & Mild & Moderate & Severe & \\
\hline & \multirow[t]{2}{*}{ Low } & 1 & 2 & 18 & \multirow[t]{4}{*}{-.093} \\
\hline & & $1.70 \%$ & $3.3 \%$ & $30.0 \%$ & \\
\hline & \multirow[t]{2}{*}{ Normal } & 4 & 4 & 31 & \\
\hline & & $6.7 \%$ & $6.7 \%$ & $51.7 \%$ & \\
\hline \multirow{2}{*}{\multicolumn{2}{|c|}{ Total }} & 5 & 6 & 49 & 60 \\
\hline & & $8.3 \%$ & $10.0 \%$ & $81.7 \%$ & $100 \%$ \\
\hline
\end{tabular}

** Significant at 0.01 level

*Significant at 0.05 level

(C) 2014 www.ijip.in

July-September 2014

$95 \mid \mathrm{P}$ a g e 
The International Journal of Indian Psychology: Volume: 01 | Issue: 04 | ISSN 2348-5396

Table 5: Correlation of Cannabis Use Dependents Identification Test (CUDIT) and Raqon Emotional Intelligence Test (REIT) of Cannabis Dependents

\begin{tabular}{|c|c|c|c|c|c|}
\hline \multirow{2}{*}{\begin{tabular}{|l} 
Group \\
REIT
\end{tabular}} & \multicolumn{4}{|c|}{ CUDIT } & \multirow[t]{2}{*}{$\mathrm{R}$} \\
\hline & Variable & Advisable & $\begin{array}{l}\text { Advisable } \\
\& \\
\text { Counseling }\end{array}$ & $\begin{array}{l}\text { Diagnostic } \\
\text { Evaluation } \\
\& \\
\text { Treatment }\end{array}$ & \\
\hline & \multirow[t]{2}{*}{ Low } & 0 & 1 & 14 & \multirow[t]{4}{*}{-0.083} \\
\hline & & 0.0 & 1.7 & 23.3 & \\
\hline & \multirow[t]{2}{*}{ Normal } & 3 & 1 & 41 & \\
\hline & & 5.0 & 1.7 & 68.3 & \\
\hline \multirow[t]{2}{*}{ Total } & & 3 & 2 & 55 & 60 \\
\hline & & 5 & 3.3 & 91.7 & 100 \\
\hline
\end{tabular}

** Significant at 0.01 level

*Significant at 0.05 level

Table 6: Correlation of Cannabis Use Dependents Identification Test (CUDIT) and Rosenberg Self Esteem Scale (RSES) of Cannabis Dependents

\begin{tabular}{|c|c|c|c|c|c|}
\hline Group & 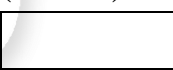 & \multicolumn{3}{|c|}{ cuDIT elnationa } & \multirow[t]{2}{*}{ Rlina } \\
\hline \multirow[t]{5}{*}{ RSE } & Variable & Advisable & $\begin{array}{l}\text { Advisable } \\
\& \\
\text { Counseling }\end{array}$ & $\begin{array}{l}\text { Diagnostic } \\
\text { Evaluation } \\
\& \\
\text { Treatment }\end{array}$ & \\
\hline & \multirow[t]{2}{*}{ Low } & 1 & 0 & 7 & \multirow{4}{*}{.099} \\
\hline & & $1.7 \%$ & $0.0 \%$ & $11.7 \%$ & \\
\hline & Normal & 2 & 2 & 48 & \\
\hline & & $3.3 \%$ & $3.3 \%$ & $80.0 \%$ & \\
\hline Total & & 3 & 2 & 55 & 60 \\
\hline & & $5 \%$ & $3.3 \%$ & $91.7 \%$ & $100 \%$ \\
\hline
\end{tabular}

** Significant at 0.01 level

*Significant at 0.05 level 